\title{
MANUAL TÉCNICO DE EXECUÇÃO PARA PISOS INDUSTRIAIS DE CONCRETO ARMADO COMO FORMA DE PREVENÇÃO DE MANIFESTAÇÕES PATOLÓGICAS
}

\author{
COSTA, ÁLVARO \\ Engenheiro Civil \\ Centro Universitário da Serra Gaúcha \\ Rio Grande do Sul; Brasil \\ alvaro-18093@hotmail.com
}

\author{
NUNES, DAVID BRANDÃO \\ Doutorando em Engenharia Civil \\ Universidade do Vale do Rio dos Sinos \\ Rio Grande do Sul; Brasil \\ davidbrnunes@gmail.com
}

\author{
JORDANI, BÁRBARA \\ Doutoranda em Engenharia Civil \\ Universidade do Vale do Rio dos Sinos \\ Rio Grande do Sul; Brasil \\ bbjordani@gmail.com
}

\section{RESUMO}

Os pisos industriais são estruturas que fundamentam todo o sistema de produção de uma indústria, onde suas atividades operacionais acontecem e sua funcionalidade é de grande importância para que não comprometa a logística envolvida e o bem-estar do usuário. No entanto, muitas dessas estruturas não levam atenção necessária, surgindo durante sua utilização diversas manifestações patológicas, que causam má funcionalidade e impactos negativos, que são ocasionados pela atribuição e utilização incorreta do piso industrial durante sua vida útil. Logo, esses problemas influenciam diretamente na linha de produção e consequentemente o elevado custo em manutenções e reparos. Portanto, para que toda essa gestão fique dentro dos critérios aceitaveis, três apontamentos são indispensáveis: o piso industrial deverá contemplar projeto, dimensionamento e execução bem estruturados. Sendo assim, este estudo tem por objetivo desenvolver um manual técnico voltado para pisos industriais de concreto armado, visando minimizar o surgimento de manifestações patológicas. Este material contribui no momento de planejamento e execução dessas estruturas, focando no planejamento e na redução de possíveis erros, evitando problemas futuros.

\section{Palavras-chave: Pisos, industrial, manual, concreto.}

\begin{abstract}
The Industrial floors are structures that underpin the entire production system of an industry, where its operational activities take place and its functionality is of great importance so that it does not compromise the logistics involved and the well-being of the user. However, many of these structures do not take necessary attention, appearing during their use several pathological manifestations, which cause poor functionality and negative impacts, which are caused by the incorrect allocation and use of the industrial floor during its useful life. Therefore, these problems directly influence the production line and consequently the high cost of maintenance and repairs. Therefore, in order for all this management to be within the acceptable criteria, three notes are indispensable: the industrial floor should include well-structured design, sizing and execution. Thus, this study aims to develop a technical manual aimed at industrial floors of reinforced concrete, in order to minimize the emergence of pathological manifestations. This material contributes at the moment of planning and execution of these structures, focusing on planning and reducing potential errors, avoiding future problems.
\end{abstract}

Keywords: floors, industrial, manual, concrete. 


\section{INTRODUÇÃO}

O surgimento das manifestações patológicas em pisos industriais de concreto, são ocasionados por falhas no projeto e falhas na execução, além do mau dimensionamento dessas estruturas. Cristelli (2010) destaca que esses erros causam uma série de consequencias que impactam diretamente na funcionalidade das operações industriais, gerando gastos com manutenções, interferências na produção logística, contaminações, restrições de cargas, dentre outras. Segundo o autor, dependendo do estado de recuperação do piso industrial, podem chegar a custos expressamente altos, podendo chegar a equivalencia de um novo pavimento. No entanto, quando identificado o surgimento da manifestação patológica, recomenta-se primeiramente a identificação e classificação do problema, para haver o planejamento e recuperação dessa estrutura danificada, levando em consideração às diversas variedades de materiais empregados na recuperação do piso.

Pode-se afirmar para que haja a melhoria adequada, deve-se criar um projeto de recuperação que identifique os pontos a serem recuperados, faça o isolamento da área e posteriormente a sua devida recuperação. Cristelli (2010) ainda comenta que, às mafifestações patológicas surgem devido ao agente acelerador, impostos sobre os pisos industriais, como a atuação de sobrecargas móveis ou fixas, impactos mecânicos, equipamentos que possuem rodas de aço, uso de empilhadeiras de maneira inadequada, falta de manutenções nas juntas de dilatações que possibilitam infiltrações e sua contaminação.

Segundo a ANAPRE (2009) ressalta que os pisos industriais apresentam manifestações patológicas desde sua fase inicial como o projeto até a sua utilização. Também destaca alguns causadores como ausência de projetos, especificações inadequadas, redução excessiva de custo não levando em considereção a qualidade, ausência de controle tecnológico, procedimentos inadequados na hora da execução, contratos impróprios, mau uso na sua utilização e ausência de normas auxiliadoras.

Na pesquisa realizada por Soares (2017) o autor destaca que vários pesquisadores estão em busca de alternativas para identificar as causas que surgem às manifestações patológicas, dentre elas os problemas com o surgimento de fissuras, ruptura da placa de concreto, empenamento das bordas, esborcinamento das juntas de dilatação, entre outros. Destaca ainda que, os problemas de fissuração vêm desde a sub-base mau projetada e mau executada, permitindo a percolação dos agentes físicos e químicos que causam esta obstrução, que podem ocasionar o colapso de toda a estrutura.

A falta de especialização dos profissionais também é outro fator determinante, uma vez que, visam somente as questões estruturais da placa de concreto, deixando ausente outros aspectos fundamentais para o desempenho do piso. Chodounsky e Viecili (2007) indicam que geralmente os problemas patológicos que surgem nos pisos são influenciados desde a preparação da base, os materiais utilizados e a execução, ficando fora somente a parte estrutural do piso, onde os problemas são mais ausentes. De acordo com este estudo, nos pisos industriais podem ocorrer problemas relacionados com a fundação e a esforços de tração sobre o concreto. Entretanto, as cargas estáticas e dinâmicas são as principais causas patológicas, causando fissuras sobre o piso.

Na tabela 1 é apresentado os dados de autores que foram selecionados por Cristelli (2010), podendo explanar as causas, prevenções e as devidas recuperações de manifestações patológicas com maior incidencia em pisos indústrias. Dentro deste contexto, este estudo tem por objetivo desenvolver um manual técnico voltado para pisos industriais de concreto armado, visando minimizar o surgimento de manifestações patológicas. 
Tabela 1 - Especificações de manifestações patológicas.

\begin{tabular}{|c|c|c|c|c|}
\hline Patologia & Descrição & Causa & Prevenção & Recuperação \\
\hline \multirow[b]{2}{*}{ Delaminação } & \multirow[b]{2}{*}{$\begin{array}{l}\text { Destacamento da camada } \\
\text { superficial de acabamento, } \\
\text { cuja espessura varia de } 2 \mathrm{~mm} \\
\text { a } 4 \mathrm{~mm} \text {. }\end{array}$} & \multirow[b]{2}{*}{$\begin{array}{l}\text { Selamento superficial prematuro que } \\
\text { impede a exsudação da água do } \\
\text { concreto, gerando pressões internas } \\
\text { na camada impermeável de selante. }\end{array}$} & $\begin{array}{l}\text { Controle da umidade do substrato (placa } \\
\text { de concreto) antes de aplicação de } \\
\text { materiais formadores de filme } \\
\text { impermeável. }\end{array}$ & \multirow{2}{*}{$\begin{array}{l}\text { Reparo com argamassas poliméricas } \\
\text { oucimentícias modificadas com polimeros. } \\
\text { Recorte da área danificada, regularização da } \\
\text { superficie, aplicação de um primer e } \\
\text { argamassa. Executar processo de cura } \\
\text { adequado e lixar cas necessário. }\end{array}$} \\
\hline & & & $\begin{array}{l}\text { Controle da dosagem do concreto evitando } \\
\text { emprego de grandes quantidades de } \\
\text { aditivos incorporadores de ar, retardadores } \\
\text { de pega ou agregados miúdos de baixa } \\
\text { granulometria. Fator água/cimento } \\
\text { adequado. }\end{array}$ & \\
\hline $\begin{array}{l}\text { Desgaste } \\
\text { Superficial }\end{array}$ & $\begin{array}{l}\text { Desprendimento do material } \\
\text { superficial do piso, grãos de } \\
\text { areia e pó de cimento. }\end{array}$ & $\begin{array}{l}\text { Utilização de concreto de baixa } \\
\text { resistência, tratamento superficial } \\
\text { incorreto, concreto com exsudação } \\
\text { excessiva ou cura inadequada. } \\
\text { Ataques químicos e má utilização do } \\
\text { piso. }\end{array}$ & $\begin{array}{l}\text { Especialização da resistência do concreto } \\
\text { com base na utilização do piso. Controle } \\
\text { dos processos executivos de acabamento, } \\
\text { cura e tratamento superficial. }\end{array}$ & $\begin{array}{l}\text { Fechamento da porosidade superficial } \\
\text { através de aplicação de endurecedor químico } \\
\text { em duas demãos. Lapidação da superficie } \\
\text { com ferramentas diamantadas (até grana } \\
3000 \text { ). Aplicação de RAD argamassados } \\
\text { epoxidicos ou uretânicos sob substrato } \\
\text { preparado. }\end{array}$ \\
\hline \multirow{3}{*}{ Manchas } & \multirow{3}{*}{$\begin{array}{l}\text { Formação de manchas que se } \\
\text { destacam da cor padrão do } \\
\text { concreto aplicado no pixo, } \\
\text { proveniente dos processos de } \\
\text { hidratação e carbonatação do } \\
\text { concreto. }\end{array}$} & $\begin{array}{l}\text { Atraso no processo de concretagem } \\
\text { e consequente pega diferenciada do } \\
\text { concreto. }\end{array}$ & $\begin{array}{l}\text { Definição prévia de plano de concretagem } \\
\text { e de cálculo de volume de material } \\
\text { necessário para cada placa. }\end{array}$ & \multirow{3}{*}{$\begin{array}{l}\text { A cor da superficie do concreto tende a se } \\
\text { uniformizar com o tempo e, após alguns } \\
\text { meses, as manchas podem desaparecer. } \\
\text { Caso os aspectos estéticos sejam } \\
\text { primordiais, pode-se aplicar uma pintura de } \\
\text { resistência compativel com as atividades } \\
\text { previstas. Esta alternativa gera custo extra- } \\
\text { e planejado. }\end{array}$} \\
\hline & & $\begin{array}{l}\text { Posicionamento dos agragados } \\
\text { graúdos muito próximos da } \\
\text { superficie. }\end{array}$ & $\begin{array}{l}\text { Dosagem correta dos materiais do } \\
\text { concreto considerando sua } \\
\text { trabalhabilidade e controle do processo de } \\
\text { lançamento, adensamento e vibração. }\end{array}$ & \\
\hline & & $\begin{array}{l}\text { Processo de cura mal-executado e } \\
\text { de maneira heterogênea na } \\
\text { superficie. }\end{array}$ & $\begin{array}{l}\text { Controle do processo de cura. Garantir que } \\
\text { os agentes de cura estejam em contato } \\
\text { com toda a superficie do concreto. }\end{array}$ & \\
\hline \multirow{4}{*}{$\begin{array}{l}\text { Fissuras de } \\
\text { Retração }\end{array}$} & \multirow{4}{*}{$\begin{array}{l}\text { Fissuras regulares nas placas } \\
\text { concretadas geralmente } \\
\text { paralelas às juntas serradas. }\end{array}$} & \multirow{2}{*}{$\begin{array}{l}\text { Atraso no corte das juntas. A retraçäa } \\
\text { hidräulica na cura do concreto näo e } \\
\text { absorvida pelas juntas, impedindo } \\
\text { sua movimentação durante o periodo } \\
\text { de pega. }\end{array}$} & \multirow{2}{*}{$\begin{array}{l}\text { Executar o corte das juntas no intervalo } \\
\text { entre } 4 \text { e } 12 \text { hoas após o lançamento do } \\
\text { concreto. } U \text { tempo de pega e variàvel em } \\
\text { função do tipo de concreto utilizado. Após } \\
\text { a pega, executar imediatamente. }\end{array}$} & $\begin{array}{l}\text { Fissuras próximas às juntas (de } 5 \mathrm{~cm} \text { a } 10 \\
\mathrm{~cm} \text { ): aplicar selador de acordo com } \\
\text { especificação dos materiais das juntas. }\end{array}$ \\
\hline & & & & $\begin{array}{l}\text { rissuras mais atastadas: estabilizaçäo por } \\
\text { colagem com material epoxidico/poliuretano, } \\
\text { ou pela costura com barras de aço inclinadas } \\
\text { na lateral da fissura, sendo estas coladas e } \\
\text { seladas material à base de resina epóxi. }\end{array}$ \\
\hline & & $\begin{array}{l}\text { Reforço insuficiente ou Restrição à } \\
\text { movimentação da placa. }\end{array}$ & $\begin{array}{l}\text { Detalhamento das juntas e mecanismos } \\
\text { de transferência de carga devidamente } \\
\text { domensionados e posicionados. }\end{array}$ & $\begin{array}{l}\text { Execução de juntas complementares } \\
\text { tratadas para garantir a transferência de } \\
\text { carga entre as placas. }\end{array}$ \\
\hline & & $\begin{array}{l}\text { Deficiências no preparo ou } \\
\text { especificação de tratamento da base. }\end{array}$ & $\begin{array}{l}\text { Procedimento criterioso de execução com } \\
\text { base no projeto (atenção aos aspectos de } \\
\text { caracterização da capacidade de suporte } \\
\text { do solo e tratamento adequado das sub- } \\
\text { bases.) }\end{array}$ & $\begin{array}{l}\text { Execução de trechos com armação } \\
\text { complementar de combate à tração e } \\
\text { empenamento da placa. }\end{array}$ \\
\hline $\begin{array}{l}\text { Desplacamento } \\
\text { (corrosão das } \\
\text { armaduras) }\end{array}$ & $\begin{array}{l}\text { Desplacamento da camada de } \\
\text { cobrimento do concreto sob } \\
\text { tensões de expansão } \\
\text { volumétrica das armaduras. }\end{array}$ & $\begin{array}{l}\text { Penetração de cloretos e dióxidos de } \\
\text { carbono, nas placas do piso } \\
\text { causando depassivação das } \\
\text { armaduras (de controle de retração, } \\
\text { de combate à tração e até mesmo } \\
\text { das fibras de aço) e posterior } \\
\text { processo de corrosão das } \\
\text { armaduras. Aumento do volume das } \\
\text { ferragens causado pela corrosão } \\
\text { destes elementos. }\end{array}$ & $\begin{array}{l}\text { Execução de cobrimento com espessura } \\
\text { adequada e concretagem adequada para } \\
\text { evitar elevada porosidade (baixo fator } \\
\text { água/cimento, vibração adequada). } \\
\text { Tratamento contra umidade: instação de } \\
\text { barreira de vapor, selamento das juntas e } \\
\text { critérios na seleção dos métodos e } \\
\text { materiais de acabamento superficial. }\end{array}$ & $\begin{array}{l}\text { Delimitação da área afetada, remoção do } \\
\text { concreto deterioredo. Limpeza das } \\
\text { superficies. Tratamento e/ou reforço } \\
\text { estrutural das armaduras. Aplicação de } \\
\text { camada para selamento e ponte de } \\
\text { aderência. Aplicação da argamassa de alto } \\
\text { desempenho, regularização e cura } \\
\text { adequada. }\end{array}$ \\
\hline
\end{tabular}

Fonte: Cristelli (2007, p. 148).

\section{METODOLOGIA}

Muitas das manifestações patológicas que surgem em pisos industriais são ocasionadas por erros de projeto, ou até mesmo a sua ausência, mau dimensionamento da estrutura e erros no momento da execução. Essas ocorrências são causadas pela falta de conhecimento, mão de obra não qualificada e métodos construtivos errôneos, que em conjunto contribuem na geração de danos a essa estrutura, ocasionado riscos ao usuário, mau desempenho a consequência de custos elevados em reparos.

Diante disto, com embasamento realizado pelas bibliografias especializadas em pisos industriais, foi possível verificar que há poucos materiais compactos e simplificados focados na execução e direcionado para profissionais desta área. 
Neste tópico o foco principal foi a criação de um manual técnico para pisos industriais de concreto armado, visando elencar boas práticas executivas e fornecendo experiências vivenciadas em campo.

Em análise das bibliografias que sustentam o desempenho e funcionalidade de pisos industriais, foi possível elencar as principais diretrizes que irão proporcionar ao executor, uma linha de produção eficácia. Estas diretrizes, embasaram a metodologia desde estudo na criação de etapas construtivas, onde destaca-se suas principais aplicações, visando o controle de materiais e todo o processo executivo fundamentado em práticas sucintas. Possibilitando também, a clareza em observar e prevenir erros praticados em obra, que interferem no desempenho funcional da estrutura do piso industrial.

O manual técnico trata-se de um cronograma pelo qual é baseado na sequência que toda a obra de pisos industriais de concreto armado deverá seguir. O resultado garantirá uma estrutura de qualidade e alto desempenho independente da sua função final, minimizando ao máximo o surgimento das manifestações patológicas. No entanto, salienta-se que este manual técnico não exime a presença do engenheiro civil na obra, pois todo o acompanhamento e fiscalização é fundamental para que o manual seja colocado em prática e de maneira correta, caso for necessário, a vivência do profissional poderá contribuir na inteiração de todos os fatores.

\section{APRESENTAÇÃO E ANÁLISE DOS RESULTADOS}

\subsection{Criação do manual técnico}

O manual é constituído por 16 etapas, está estritamente relacionado ao piso de concreto armado sem o dimensionamento de fundações profundas ou rasas, portanto, é necessário que haja um estudo preliminar e verificação da estrutura e solo, seja feita esta análise concomitante ao manual técnico.

\subsection{1 $1^{\mathrm{a}}$ Etapa: Conhecer o local}

O usuário solicitante juntamente com o engenheiro, deve-se reportar ao local onde planeja-se executar a obra, conhecendo toda a região que envolverá a estrutura. Uma das primeiras análises é a verificação do solo presente no local, visualizar às caracteristicas de corte ou aterro. E os tipos de solo presente no local com uma empresa técnica especializada, analisando as propriedades como índice de resistência e deformabilidade deste material, por meio de ensaios específicos. Como ensaios SPT, CBR, dentre outros se necessário.

\subsubsection{2 $2^{\mathrm{a}}$ Etapa: Fundações}

De acordo com as análises técnicas do solo coletadas em campo, o engenheiro projetista deverá definir se a estrutura dependerá da implantação de fundações atente sempre aos parâmetros da norma NBR 6122:2010. Caso não seja necessário, deve-se analisar a necessidade de estabilização do solo, com materiais adequados.

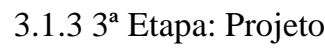

O usuário deverá solicitar ao engenheiro a elaboração de um projeto para o piso industrial, no qual haverá indicadores como:

- fundações;

- dados de sondagem;

- reforço do subleito (em casos);

- sub-base;

- grau de compactação;

- barreira de vapor;

- índice de planicidade e nivelamento

- armaduras superior e inferior (em casos);

- especificação do concreto;

- dimensionamento de juntas;

- método de cura;

- instalações;

- dentre outras se necessário. 
Todas essas edpecificações, serão exigidas conforme os carregamentos solicitados que o piso receberá, portanto, é fundamental que as informações sejam comunicadas ao engenheiro projetista. Com isso, torna-se maior a garantia do desmpenho e durabilidade do piso industrial. O projeto é necesário pois estabelece além das características estruturais, os critérios de adequabilidade, utilização de recursos e controle de custos.

\subsubsection{4ªpa: Terreno - nivelamento e compactação}

Conforme os resultados dos ensáios técnicos do solo, é verificado se há necessidade de reforço do subleito com materiais estabilizantes, que levarão ao aumento da restência do mesmo, posteriormente será feito os procedimentos de nivelamento e compactação. A compactação deverá ser escalada em projeto pelo GC (grau de compactação) que será executado em obra, portanto, é de grande importância que esse índice seja cumprido exatamente como especificação em projeto.

- exemplo: GC de 100\%, valores próximos como $85 \%$ ou $93 \%$ não devem aceitos, visto que, representam solo praticamente solto ou mau compactado.

Para ter o conhecimento do alcance esperado do GC, é indicado o ensaio de método do frasco de areia, que mostrará o peso especifico do solo em campo, junto com o peso especifico máximo obtido em laboratório, terá o GC em porcentagem $(\mathrm{GC}=($ Peso especifico solo em campo/Peso especifico máximo em lab.) X 100. A compactação deverá ter o acompanhamento de equipamentos com controle de nivelamento das camadas, como nível óptico e laser que auxiliam para que haja uma conformidade mais precisa das camadas e na compactação total do terreno, controlando também os caimentos previstos em projeto. Também deve-se atentar ao controle de números de passadas entre 6 a 12, insistir com o aumento de passadas poderá produzir na perda do GC, onde a estrutura acabou de ser formada.

Os equipamentos de compactação também são importantes e suas funcionalidades são para solos especificados. E para os locais próximos à interferências, é recomendado placa vibratória ou sapo mecânico.

\subsubsection{Etapa: Execução da sub-base}

Após a regularização e compactação do solo, a sub-base é aplicada sobre o terreno conforme especificação do projeto, bem como seu tipo espessura das camadas onde deverá ser devidamente compactada, oferecendo o reforço estrutural no suporte de apoio do piso garantindo maior resistência. Além de reforço estrutural, a sub-base é responsável pela eliminação do bombeamento dos finos plásticos do solo até a superfície do piso, atuando para que não haja a perda de resistência do subleito, desplacamento e trincas na placa de concreto. A sua utilização, proporciona o dimensionamento menor da espessura da placa de concreto, reduzindo diretamente no custo.

As sub-bases possuem GC e deverão ser respeitados para que não acarrete problemas de assentamento e deformações no piso, e a sua espessura poderá variar conforme os carregamentos.

A sub-base somente poderá ser ausentada quando análise de parâmetros como:

- o piso receberá carregamentos baixos;

- o subleito tenha capacidade de suporte;

- $\quad$ isenção de bombeamento de finos;

- clima predominante seco.

Cabe ainda ressaltar que caso a sub-base possa ser isentada, não é recomendado pois ela garante uma resistência maior e uma diminuição da espessura da placa do concreto.

\subsection{6 $6^{\mathrm{a}}$ Etapa: Aplicação da lona plástica}

Também conhecida como barreira de vapor, a lona é colocada após a sub-base estar compactada, seguindo as seguintes funções:

- impedir que a umidade transmitida pelo solo seja transferida para a placa de concreto, esta umidade vem em forma de vapor podendo condensar e formar bolhas de água no piso.

- camada deslizante da placa de concreto, onde reduz o atrito entre a placa e a sub-base. Estas tensões que surgem são devidas as variações térmicas.

- mantém a hidratação do concreto no período de cura, fazendo com que à agua do concreto não seja absorvida pela sub-base. 
Para a utilização da lona, o ideal de espessura média é de 150 a 200 micras, podendo ser revisada pelo engenheiro projetista. Também é necessário um transpasse mínimo de 30 centímetros entre elas, para que não ocorra a passagem da umidade.

\subsection{7 $7^{\mathrm{a}}$ Etapa: Montagem da fôrmas}

As fôrmas irão delimitar as áreas concretadas conforme as especificações do projeto. São utilizadas geralmente fôrmas metálicas e de madeira de lei, oferecendo vantagens no seu alinhamento. Salienta-se alguns itens importantes no momento da montagem das fôrmas:

- $\quad$ as fôrmas deverão estar bem posicionadas, sendo acompanhadas de nível óptico ou laser para assegurar o seu nivelamento e alinhamento;

- $\quad$ devem ser bem fixadas por escoras de barras de aço ou concreto, para que não cedam com as pressões na hora da concretagem e a utilização de equipamentos;

- devem possuir furos laterais alinhados para seja possível o encaixe das barras de transferência;

- devem estar limpas para que não haja interferências na placa de concreto;

- cuidar com o empenamento para que não comprometa o nivelamento do piso;

- $\quad$ após 12 horas de concretagem, as fôrmas poderão ser retiradas não ultrapassando o limite de 26 horas;3

- o plano de concretagem pode ser variado, suas etapas podem ser mudadas conforme adequabilidade da obra e utilização de equipamentos.

\subsubsection{Etapa: Montagem das armaduras}

De acordo com as especificações do projeto, as armaduras terão função estrutural com desempenho e durabilidade do piso industrial, também controlam as fissuras causadas pela retração do concreto. As armaduras poderão ser aplicadas pelo método simples ou dupla, onde armaduras simples são empregadas somente armaduras superiores, caso seja dupla, o piso terá a presença de armaduras na parte inferior e superior.

Essas armaduras serão apoiadas sobre espaçadores. Armaduras inferiores são apoiadas em espaçadores plásticos ou argamassados e armaduras superiores em espaçadores metálicos (treliças).

Os cobrimentos das armaduras devem ser respeitados, indica-se que na armadura inferior o cobrimento seja de $30 \mathrm{~mm}$ em relação a base, para alcançar a sua função estrutural. Para as armaduras superiores é recomendado que o posicionamento seja de $1 / 3$ da espessura da placa não ultrapassando $50 \mathrm{~mm}$.

\subsubsection{9ª Etapa: Espaçadores}

Os espaçadores têm como finalidade apoiar as armaduras que serão compostas no piso industrial. Portanto, nas armaduras superiores os espaçadores treliças mais utilizados nas alturas de $6 \mathrm{~cm}, 8 \mathrm{~cm}, 12 \mathrm{~cm}, 16 \mathrm{~cm}, 20 \mathrm{~cm}$ e $25 \mathrm{~cm}$. Não são recomendados a utilização de outros materiais como madeiras, tijolos, e pedaços de concretos como função de espaçadores, pois podem comprometer a estrutura do piso causando o surgimento de manifestações patológicas.

\subsubsection{0ª Etapa: Telas soldadas}

As telas soldadas serão especificadas em projeto, portanto, a sua função é de grande importância para a parte estrutural do piso. As telas superiores têm a finalidade de resistir as tensões de retração do concreto e as telas inferiores, resistir os esforços das tensões de tração na flexão. O tipo de tela mais empregada em pisos industriais são as telas com malhas do tipo Q, onde representam as malhas quadradas com área de aço longitudinal e transversal iguais. Essas telas possuem dimensões de 2,40m de largura por 6,00 $\mathrm{m}$ de comprimento.

As telas deverão ser amarradas com arame recozido nas treliças para que não ocorra o deslocamento no momento da concretagem. Devem estar sobrepostas de duas malhas na parte superior, e na parte inferior deve haver a sobreposição de uma malha. Isso faz com que tenha uma continuidade em toda a sua extensão. Outro parâmetro importante que deve ser analisado no momento das aplicações das malhas são as distâncias máximas dos espaçadores que às apoiam. Portanto, é preciso ter cuidado com a movimentação de operadores e das tubulações das bombas de concreto que ficam escoradas nas telas montadas, podendo ocorrer o deslocamento das mesmas.

No encontro com pilares, indica-se o reforço com telas de 50 centímetros para cada lado do pilar e 50 centímetros a frente do pilar, este método reduz o índice de fissuras causadas pelo trabalho independente dessas duas estruturas, o piso e o pilar. Recomenda-se também, o reforço com tela nas entradas do pavilhão que terão o tráfego de altos 
carregamentos como carretas, caminhões e empilhadeiras, o reforço dá-se com a implantação da tela de 0,80 à 1,00m de largura em todo o comprimento da borda onde será a entrada.

\subsubsection{1 $11^{\mathrm{a}}$ Etapa: Barras de transferência}

As barras de transferência têm função estrutural no piso industrial, devem ser empregadas em duas situações:

- transferência de cargas entre as placas: devem ser posicionadas corretamente distando $30 \mathrm{~cm}$ entre si nas fôrmas que delimitam as placas formando às juntas de encontro. Neste momento, deve ser engraxada metade da barra de transferência e a outra não, para que haja uma movimentação contrativa da placa que desliza pelo concreto. Isso permite que as tensões que são impostas sobre o piso sejam amortizadas, prevenindo problemas de rompimento da placa de concreto e trincas.

- caranguejos: são as barras de transferências apoiadas em espaçadores treliças, onde as barras são colocadas em paralelo entre si distando $30 \mathrm{~cm}$. Neste caso, os caranguejos serão colocados nas juntas serradas, e recomenda-se que a barra esteja totalmente engraxada, pois permitirá que a junta trabalhe de maneira adequada ao receber os esforços.

No posicionamento dos caranguejos que passaram as juntas serradas, as telas não poderão passar sobre o seu meio, devendo ocorrer um corte de 5 centímetros para cada lado, este processo faz com que a função do caranguejo não seja eliminada. A especificação de espessura das barras de transferências também é informada pelo projetista, e extremamente dependem das cargas atuantes sobre o piso, espessura da placa de concreto e da tela soldada.

\subsubsection{2a Etapa: Dimensionamento das juntas}

As juntas dimensionadas pelo projetista dever ser estritamente seguidas, pois são os pontos mais frágeis do piso industrial. Portanto, quanto menor o número de juntas, maior será a durabilidade do piso.

As juntas permitem que ocorram as movimentações de contração e expansão do concreto, e transmitem entre placas as cargas solicitadas, também são asseguradas por manter a planicidade, desempenho e rolamento do piso.

Recomendações fundamentais para o dimensionamento das juntas:

- o piso deve trabalhar isoladamente em relação as outras estruturas como pilares, paredes, vigas de baldrame, máquinas. Portanto, são dimensionadas juntas de encontro que permite o livre movimento entre essas estruturas;

- $\quad$ as juntas devem ser sempre contínuas podendo ser interrompidas nas juntas de encontro;

- quando houver o encontro entre as juntas, o ângulo deve ser de $90^{\circ}$ para que não haja fissuras.

- devem ser cortadas com equipamento adequado entre 6 e 8 horas após o acabamento do piso.

- importante no dimensionamento dos cortes das juntas, dependem da espessura da placa e da dimensão total do piso. Para pisos de grandes dimensões, indicado não ultrapassar placas maiores que $100 \mathrm{~m}^{2}$. No entanto, deve-se atentar aos parâmetros estabelecidos pelo engenheiro projetista.

Nos pisos industriais, pode-se dimensionar 3 tipos de juntas, sendo elas juntas de construção (JC), juntas serradas (JS) e juntas de encontro (JE). As juntas de construção, são formadas pelas delimitações dos panos, são executadas entre as placas que ficam as barras de transferência. Recomenda-se que sua projeção seja feita onde não tenha tráfego intenso e seu corte a uma profundidade de até $2,5 \mathrm{~cm}$.

As juntas serradas, são empregadas para que haja a acomodação das placas geradas pelas tensões de retração do concreto. Nessas juntas que são expostos os caranguejos, e devem ter o corte a uma profundidade de 1/3 da espessura da placa. Para as juntas de encontro, são projetadas quando a contato com outras estruturas, como paredes, pilares, vigas de baldrames. Isso torna-se possível as estruturas trabalhem livremente considerando os fatores de retração e variações térmicas. Com isso, para marcar essa delimitação, o material mais recomendado é o E.V.A. (Etil, Vinil e Acetato), borracha não-tóxica, com a mesma espessura do piso.

\subsubsection{3 $13^{\mathrm{a}}$ Etapa: Concreto}

A especificação do concreto será prevista em projeto, portanto deve-se atentar juntamente com a central dosadora do concreto quanto ao traço exigido para o piso industrial. As resistências do concreto variam de mínimo fck $25 \mathrm{MPa}$, podendo ter como preferência fck $30 \mathrm{MPa}$.

\subsubsection{4 $14^{\mathrm{a}}$ Etapa: Concretagem}


No momento da concretagem devem ser observados vários cuidados para que não cause problemas com o piso:

- combinar juntamente com a central dosadora do concreto uma sequência de encaminhamento de caminhões betoneira;

- é recomendado que não ultrapasse 90 minutos de intervalos de caminhões, visto que pode acarretar problemas com o acabamento superficial;

- para pisos de concreto armado, é recomendado também o caminhão bomba, pois, no momento da concretagem não haja interferências do caminhão sobre as armaduras. As mangueiras da bomba devem ser apoiadas sobre cavaletes ou pallets de madeira, que não desloquem a armadura posicionada;

- na chegada do caminhão é necessário verificar se o concreto está conforme o solicitado, juntamente com o seu lacre não violado;

- fazer o slump test, (teste de abatimento do concreto) realizado com o ensaio tronco cone com abatimento entre $80 \mathrm{~mm}$ e $120 \mathrm{~mm}$, deve ser feito em todos os caminhões;

- no momento do adensamento do concreto deve haver equipamentos apropriados, como o vibrador de imersão, para que seja feita toda a imersão do concreto pelas entranhas das armaduras, cuidando para que não haja o deslocamento das armaduras posicionadas;

- deve-se ter cuidado com as fôrmas para que não haja deslocamento;

- para o nivelamento e planicidade do piso deve contar com a utilização dos equipamentos nível óptico e laser;

- $\quad$ no nivelamento do concreto, podem ser empregadas as réguas de alumínio ou réguas vibratórias;

É recomendado que o usuário contrate uma empresa que faça o controle tecnológico dos ensaios do concreto, para que haja uma garantia da parte do contratante quanto as especificações técnicas do concreto que está sendo utilizado.

\subsubsection{5 $15^{\mathrm{a}}$ Etapa: Acabamento superficial}

O acabamento superficial garante vários benefícios como, a facilidade de limpeza, resistência a abrasão, escoamento de líquidos, movimentação de equipamentos, durabilidade. Após realizado o desempeno com a régua de alumínio, pode-se empregar outros equipamentos para o acabamento do piso industrial. A utilização da alisadora mecânica que pode ser simples ou dupla hélices que fazem todo o acabamento polido no piso.

Para áreas externas é recomendado no pavimento o acabamento vassourado, que são ranhuras no pavimento feitas antes da pega no concreto e geram texturas antiaderente, garantindo a segurança no tráfego, usualmente em rampas. $\mathrm{O}$ acabamento discado também pode ser recomendado em parte externa.

Para pisos industriais que receberem pintura ou algum outro tipo de revestimento é recomendado que seja realizado um acabamento superficial "camurçado", onde a textura que ficará na superfície do piso é propicia para ancoragem de revestimentos.

\subsubsection{6 ${ }^{\mathrm{a}}$ Etapa: Aplicação da cura}

Logo após o acabamento superficial é de extrema importância que se inicie o processo de cura do piso. A cura está estritamente relacionada a resistência do concreto, e sua aplicação deverá ter o máximo de cuidado, para que haja toda a hidratação uniforme do concreto e não ocorram problemas de empenamento e que fissuras por retração sejam reduzidas, e o surgimento de manchas. Com isso, pode-se ter a aplicação de dois métodos de cura no pavimento sendo elas, cura úmida e cura química.

- $\quad$ cura úmida - tem como método aplicar uma película espessa de água em todo o pavimento por 7 dias, ou com a utilização de mantas de polietileno imersas em água para que não seja evaporada. No entanto, com a utilização da manta pode ocorrer manchas na superfície do piso.

- cura química - constituída por agentes químicos, que formam uma membrana sobre a camada superficial do piso, reduzindo ou impedindo a perda da água consistida no concreto. A aplicação mecânica deverá ser uniforme, e são manuseados por bombas de baixa pressão, tendo uma aplicação suficiente. A quantidade deve ser em média de 0,15 litro $/ \mathrm{m}^{2}$ a 0,25 litro $/ \mathrm{m}^{2}$.

Em análise aos dois métodos, a cura química se destaca mais sobre a cura úmida, em:

- custo baixo em comparação outros métodos de cura;

- reduz o desperdício de água na sua utilização;

- $\quad$ elimina o monitoramento diário que a cura úmida exige;

- $\quad$ pode ser aplicado em outros tipos de acabamentos como vassourado e camurçado. 
A cura úmida geralmente não é executada com os cuidados essenciais por depender de alguns dias de aplicação, portando a cura química é aplicada uma vez, desde que corretamente torna-se melhor viável.

\subsubsection{Fluxograma do manual técnico}

Para melhor entendimento, a Figura 1 representa o fluxograma contendo às 16 etapas do manual técnico.

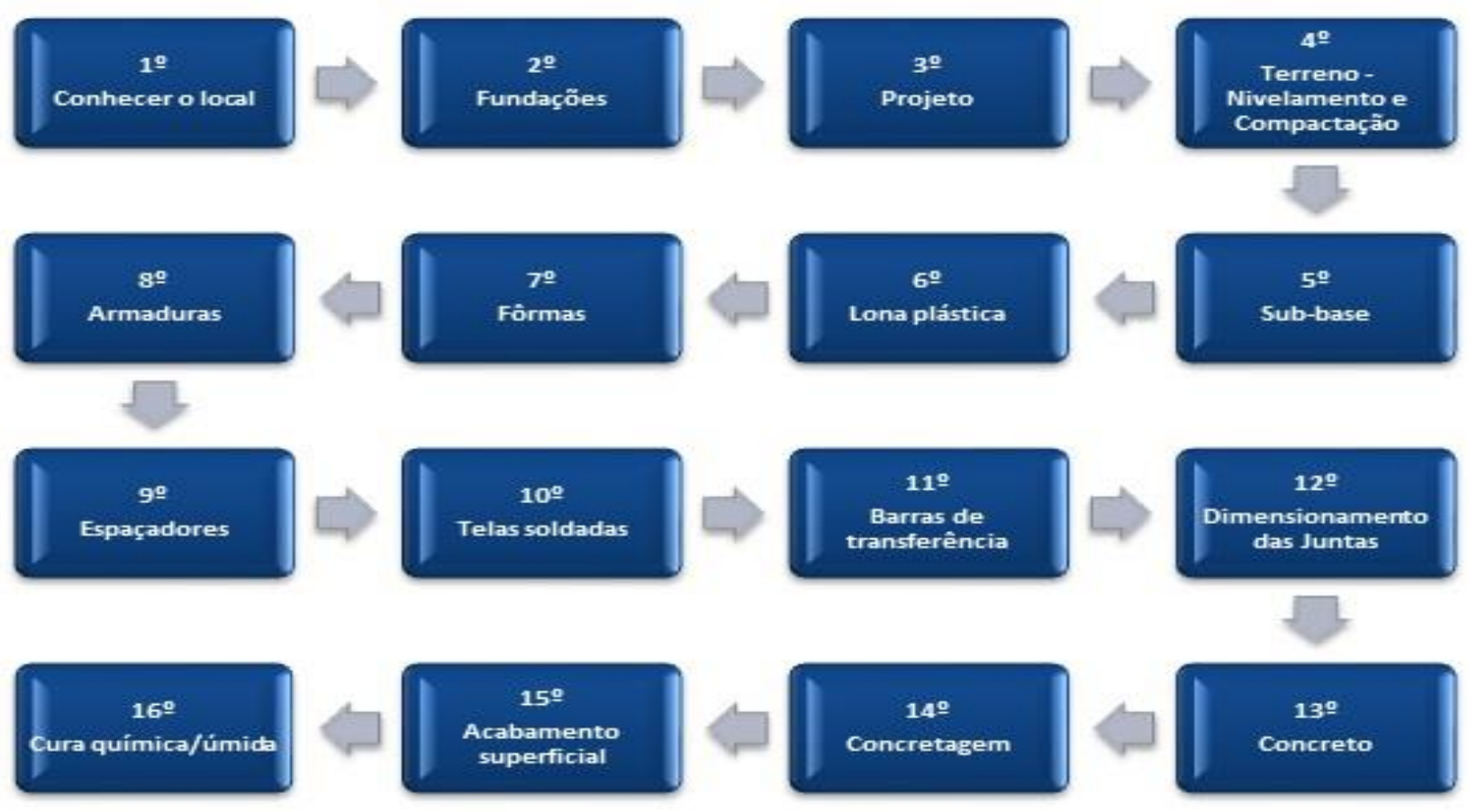

Figura 1 - Fluxograma Manual Técnico. Do Autor 2019.

\section{CONCLUSÃO}

No decorrer destes anos, as pesquisas apontaram que houve avanços nas técnicas construtivas na evolução dos pisos industriais, exigida pela crescente demanda das indústrias. Diante disso, cresceram as demandas e consequentemente os riscos aumentam, quando não há parâmetros de controle como uma norma regulamentadora, que engenheiros projetistas, executores possam adquirir bases mínimas sobre processos de projeção e execução destas estruturas.

O mau dimensionamento, ausência de projeto e erros na execução, certamente abrigam problemas futuros, causando impactos negativos como o custo extraordinário e excessivo. Estes avanços nas técnicas construtivas podem ser destacados na disponibilidade de aperfeiçoamento em cursos de execução que são oferecidos no país que discutem metodologias. No entanto, os equipamentos utilizados, como máquinas de alto custo, nem sempre estarão disponíveis para o usuário ou executor. É importante destacar que a demanda em reparos em pisos industriais é alta no Brasil, causados por diversos erros ao longo de sua projeção e execução.

Com isso, neste período de análise da pesquisa sobre pisos industriais. Os problemas com fissuração e trincas são uns das maiores manifestações ocorridas, impendido-o muitas vezes a linha de produção como fluxo, logistica de uma indústria. 
O manual técnico é recomendado somente para pisos de concreto armado, por ser destacado como uma metodologia bastante empregada hoje nos pisos industriais. Certamente existem outras técnicas que podem garantir suporte igual ou superior a esta metodologia, porém seus índices de aceitação sempre foram bem-sucedidos no momento da escolha de implantação. Para isso, a expectativa dessa ferramenta é que seja utilizada em obras ou em escritórios de projeto, com o intuito de orientar o usuário para que a execução ocorra de maneira correta, a fim de garantir o desempenho da estrutura.

\section{REFERÊNCIAS}

ANAPRE. Associação Nacional de Pisos e Revestimentos de Alto Desempenho. Disponível em: <http://www.site.anapre.org.br>. Acesso em 03 nov. 2019.
ARCELORMITTAL BRASIL. Telas soldadas,
espaçadores
treliçados.
Disponível:

<http://www.brasil.arcelormittal.com.br>. Acesso em: 10 abr. 2019.

ASSOCIAÇÃO BRASILEIRA DE NORMAS TÉCNICAS (1996). NBR-6112 - Projeto e execução de fundações. Rio de Janeiro, 1996.

ARIF, Mohammed Adel. Avaliação da medida de tenacidade do concreto reforçado com fibras de aço. 2014. 177f. Dissertação (Mestrado em Engenharia Civil) - Curso de Pós-graduação em Engenharia Civil, Universidade Federal de Uberlândia - Minas Gerais, 2014.

BRITO, Ademir do Nascimento. Projeto e execução de pavimento industrial em estruturas de concreto: ampliação de um galpão industrial em Luziânia - GO. 2016. 66 f. Monografia (Curso de Engenharia Civil) - Curso de Engenharia Civil, Centro Universitário do Distrito Federal - UDF, Brasília. 2016.

BONASSA, Márcio. Estudo comparativo entre diferentes métodos de dimensionamento ara pisos industriais de concreto armado - estudo de caso. 2010. 97 f. Monografia (Curso de Engenharia Civil) - Universidade do Extremo Sul Catarinense - UNESC, Santa Catarina, 2010.

CIMENTOS MONTES CLAROS. Método de cura para pisos industriais. Disponível: <http://www.cimentomontesclaros.com.br>. Acesso em: 15 abr. 2019.

CHODOUNSKY \& VIECILI, Marcel Aranha e Fábio André. Pisos industriais de concreto - Aspectos teóricos e executivos. São Paulo: Reggenza, 2007.

CRISTELLI, Rafael. Pavimentos industriais de concreto - análise do sistema construtivo. 2010. 161 f. Monografia (Curso de Especialização em Construção Civil) - Curso de Especialização em Construção Civil, Universidade Federal de Minas Gerais, Belo Horizonte. 2010.

CRUZ, Debora Regina. Execução de piso industrial de concreto com a utilização de fibra sintética. 2015.54 f. Monografia (Curso de Especialização em Construção Civil) - Curso de Especialização em Construção Civil, Universidade Federal de Minas Gerais, Belo Horizonte. 2015.

GASPARETTO, Wagner. Pisos e pavimentos industriais com uso de espaçadores. 2004. 3f. Artigo (Construção Civil) -São Paulo/SP.

GUIMARÃES, Diego. Pisos industriais em concreto: determinação de teores ótimos de fibras de aço e polipropileno em ensaios mecânicos. 2010. 90 f. Monografia (Curso de Engenharia Civil) - Curso de Engenharia Civil, Universidade Federal do Rio Grande do Sul, Porto Alegre. 2010.

GUIMARÃES, SILVA FILHO \& PACHECO, Diego, Luiz Carlos Pinto e Alexandre Rodrigues. Pisos industriais em concreto armado: determinação de teores ótimos de fibras de aço e polipropileno em ensaios mecânicos. IBRACON 53 $^{\circ}$ congresso brasileiro do concreto. 2011. 17f. Florianópolis - Santa Catarina, 2011.

IBTS. Instituto Brasileiro de Telas Soldadas. Disponível: 〈http://www.ibts.org.br〉. Acesso em: 05 abr. 2019. 
OLIVEIRA, Patrícia Lizi. Projeto estrutural de pavimentos rodoviários e de pisos industriais de concreto. 2000. 246 f. Dissertação (Mestrado em Engenharia de Estruturas) - Universidade de São Paulo, São Carlos - São Paulo, 2000.

ODA, Sandra. Estradas e Pavimentação. 2003. 142f. Universidade Estadual de Maringá, departamento de Engenharia Civil.

PEREIRA \& BRAGA, Wesley de Alencar e Ricardo Estanislau. Método executivo de piso industrial. Pensar Engenharia, Belo Horizonte - MG, v. 2, n. 2, p. 01-19, jul. 2014.

RODRIGUES, BOTACINI \& GASPARETTO, Públio Penna Firma, Silvia Maria e Wagner Edson. Manual Gerdau de pisos industriais. São Paulo: Pini, 2006.

RODRIGUES \& CASSARO, Públio Penna Firme e Caio Francisco. Pisos industriais de concreto armado. 1998. 88f. Artigo (Construção Civil) - São Paulo/SP.

RODRIGUES, FARIA \& SILVA, Públio Penna Firme, Breno Macedo e João Batista Rodrigues. Novos critérios para pavimentos de concreto armado. 2015. 124f. Instituto Brasileiro de Tela Soldada - São Paulo/SP.

SANTOS, Célia Moisés, Testes em execução de pisos industriais. Especialize On-line IPOG, Goiânia - GO, Edição n 10, v.1, p. 01- 21, dez. 2015.

SENEFONTE, Kleber Basílio. Diretrizes de projeto, execução e controle de pisos industriais de concreto protendido. 2007. 80 f. Monografia (MBA - Especialização em Tecnologia na Produção de Edifícios) - São Paulo/SP, 2007.

SOARES, Renan Gustavo Pacheco. Análise dos fatores intervenientes da fissuração de placa de piso de concreto apoiada sobre lajes de concreto armado. 2017. 104 f. Dissertação (Mestrado em Engenharia Civil e Ambiental) Curso de Pós-graduação em Engenharia Civil e Ambiental, Universidade Federal de Pernambuco, Caruaru, 2017.

SUPERMIX. Concreto, métodos de acabamentos superficiais em pisos industriais. Disponível: <http://www.supermix.com.br>. Acesso em: 10 maio. 2019. 